\title{
Workload Analysis of Rice Field Workers in Bali
}

\author{
I Made Anom Santiana ${ }^{1}$ I Nyoman Sutapa ${ }^{4}$ \\ Civil Engineering Department \\ Politeknik Negeri Bali \\ Bali, Indonesia \\ ${ }^{1}$ madeanomsantiana@pnb.ac.id, \\ ${ }^{4}$ nyomansutapa1965@pnb.ac.id
}

\author{
Wira Ditta Lokantara ${ }^{2}$ \\ Economics Department \\ Universitas Gadjah Mada \\ Yogyakarta, Indonesia \\ ${ }^{2}$ wiraditta@gmail.com
}

\author{
M Yusuf ${ }^{3}$ \\ Mechanical Engineering Department \\ Politeknik Negeri Bali \\ Bali, Indonesia \\ 3yusuf@pnb.ac.id
}

\begin{abstract}
Indonesia is an agricultural country. Agricultural land still extends throughout the archipelago. In modern times, there are many agricultural lands that have been done with machine tools, like the rice paddy hand tractor. Hand tractors are widely used in rural or inland rice fields. Its function is to plow the land or to loosen paddy fields before planting rice. In Bali the agricultural sector is also the basis of the economy in addition to the tourism sector and small industry. Rice fields in the area of Bali in the processing of many land use hand tractors. It should also be noted that although machine tools are designed to provide convenience for farmers, on the other hand it also has a negative influence on farmers as its users. One of the effects is that this machine makes a loud noise, causes vibration, and heavy besides the work is actually done under the intense direct sunlight. For this reason an observational study was carried out on 20 farmers or field workers who had used hand tractors in 5 regencies in Bali. We aim to evaluate the workload, through the measurement of pulse, ECPT (extra calorie due to peripheral temperature), ECPM (extra calorie due to peripheral metabolism), engine vibration, noise, wind speed, ambient temperature and humidity. The results showed that the workload of farmers was classified as heavy, ECPT > ECPM, an increase in muscle complaints and general fatigue in farmers. For this reason, an ergonomic intervention is needed for farmers cultivating rice fields in Tabanan Regency. Because ECPT> ECPM, in the ergonomics intervention, the environment influences such as noise, vibration, machine weight, solar heat must be kept as small as possible so as to reduce the workload of farmers.
\end{abstract}

Keywords-workload; exposure to heat; vibration; noise; musculoskeletal complaints; subjective complaints workload, exposure to heat, vibration; noise; skeletal muscle complaints; subjective complaints

\section{INTRODUCTION}

Indonesia is an agricultural country. Agricultural land still extends throughout the archipelago. In modern times, there are many agricultural lands that have been done with machine tools. Like the rice hand tractor. This hand tractor is widely used in rural or inland rice fields. Its function is to plow the land or to loosen paddy fields before planting rice. In Bali the agricultural sector is also the basis of the economy in addition to the tourism sector and small industry.

Although machine tools are designed to provide convenience for farmers, on the other hand they also have negative influence on farmers as the users. One of the effects is that this machine makes a loud noise, causes vibration, and has a large weight, this affects the health of the farmers. Mechanical vibration of the hand or arm will cause abnormalities in the circulation of blood and nerves and cause damage to joints and bones [1]. Noise in the workplace can reduce the comfort and calmness of work, interfere with the sense of hearing, cause hearing loss and can eventually lead to permanent deafness for workers exposed to the noise. In addition to hearing loss, noise can also cause other consequences such as increased blood pressure, accelerated heart rate, skin blood vessel tension, increased metabolism, decreased digestive activity and increased muscle tension [2], [3].

From the initial observations it is known that the workload in this process is quite heavy because of the influence of regulating the heavy direction of the tractor, the presence of vibration and noise as well as an additional burden in the form of exposure to solar heat with a long duration. Exposure to hot temperatures can cause heat exhausion, which is sweating very much, body temperature rises while the skin is dry and hot. This additional workload will increase the workload of worker [4]. Besides that, the condition of the farm land in Bali is not the type of flat land like in Java, Sumatra, or Kalimantan, but there are in terraced forms. This also adds to the difficulty of the farmers in plowing the fields using hand tractors.

From the description above, it is deemed necessary to conduct an observational study of workload, impact of vibration, noise caused by fieldworkers' hand tractors and the influence of environmental heat exposure on rice cultivators in Bali. 


\section{RESEARCH METHODOLOGY}

This research is a preliminary study conducted observationally on 20 farmers who plow rice fields using hand tractors in 5 regencies in Bali. The workload is determined by the working pulse measured using a pulse meter. Environmental temperature and humidity are measured with a Psychrometer. Noise is measured with a sound level meter. Wind speed is measured using an anemometer. Vibration is measured by vibration meter. Solar radiation heat temperature is measured with a ball thermometer. Subjective complaints are measured by fatigue and musculoskeletal complaints. Predicted fatigue of questionnaire 30 items are generally obtained with four Likert scales and musculoskeletal complaints are predicted by the Nordic Body Map questionnaire. Statistical analysis was carried out descriptively on workloads and subjective complaints from field workers who are using hand tractors.

\section{RESULTS AND DISCSUSSIONS}

\section{A. Subjects Characteristics}

The characteristics of the farmers to be in the subjects in this research are as follows:

TABLE 1. RESEARCH SUBJECTS CHARACTERISTICS

\begin{tabular}{|c|l|c|c|c|}
\hline No & \multicolumn{1}{|c|}{ Variables } & Average & SD & Range \\
\hline 1 & Age (year) & 38.27 & 2.16 & $33-42$ \\
2 & Body Weight $(\mathrm{kg})$ & 61.34 & 4.18 & $58-76$ \\
3 & Body Height $(\mathrm{cm})$ & 167.26 & 2.35 & $161.5-170.5$ \\
4 & Year of Experience (year) & 9.50 & 2.46 & $5-14$ \\
\hline
\end{tabular}

Based on the characteristics of the subject, as shown in Table 1, the age range of farmers is between 33 and 42 years. This age is still in the productive age with weight in the range of $58-76 \mathrm{~kg}$ and work experience plowing fields using hand tactors between 5 and 14 years, this shows that the physical condition of the subject is in productive conditions with sufficient work experience. Work experience is one of the factors that influence the level of worker's skills, complaints that occur in the musculoskeletal system and work productivity [2].

\section{B. Working Environment and Conditions}

The results of the measurement of the working condition at the rice field workplaces conducted from morning to evening (08.00 am to 04:00 pm) are as follows:

TABLE II. WORKING ENVIRONMENT AND CONDITIONS

\begin{tabular}{|c|c|c|c|c|}
\hline No & Variables & Average & SD & Range \\
\hline 1 & Wet Temperature $\left({ }^{\circ} \mathrm{C}\right)$ & 29.13 & 0.45 & $28.50-30.80$ \\
2 & Dry Temperature $\left({ }^{\circ} \mathrm{C}\right)$ & 32.25 & 0.61 & $30.50-35.00$ \\
3 & Relative Humidity $(\%)$ & 87.50 & 1.05 & $86-89$ \\
4 & Ball Temperature $\left({ }^{\circ} \mathrm{C}\right)$ & 32.37 & 0.35 & $31.75-32.80$ \\
5 & WBGT $\left({ }^{\circ} \mathrm{C}\right)$ & 29.98 & 0.29 & $29.56-30.41$ \\
\hline
\end{tabular}

The measurements of the noise was carried out on the ears of the field workers when the tractor operates. The results are as follows:
TABLE III. HAND TRACTOR NOISE MEASUREMENTS

\begin{tabular}{|c|c|c|}
\hline$R P M$ & Average Noise $(\mathrm{dB})$ & $S D$ \\
\hline 1000 & 86.24 & 2.17 \\
\hline 1200 & 88.41 & 2.08 \\
\hline 1400 & 93.46 & 3.12 \\
\hline
\end{tabular}

While the threshold value for noise for human to hold is $85 \mathrm{~dB}$ [5]. The vibration caused by the tractors which are measured from the hand is as follows:

TABLE IV. HAND TRACTOR VIBRATION MEASUREMENT

\begin{tabular}{|c|c|c|}
\hline$R P M$ & Average Scceleration on Hand $\left(\mathrm{m} / \mathrm{s}^{2}\right)$ & $S D$ \\
\hline 1000 & 0.67 & 0.09 \\
\hline 1200 & 0.89 & 0.11 \\
\hline 1400 & 1.19 & 0.08 \\
\hline
\end{tabular}

The working environment conditions for paddy field farmers in Tabanan Bali consist of microclimate conditions, noise and vibration in the hand tractor. Microclimate conditions as shown in Table 2, the wet temperature is at 28.5 to $30.8^{\circ} \mathrm{C}$ while the dry temperature is 30.5 to $35.0{ }^{\circ} \mathrm{C}$ and relative humidity is at $86-89 \%$. This is a condition that is not comfortable for workers. Sunburn and high humidity will give additional weight to the farmer physically at work. The threshold value of the air temperature for workers is $33.0^{\circ} \mathrm{C}$ and the relative humidity of Indonesian workers which is still relatively comfortable is between $70 \%-80 \%$ [6].

Measurement of noise and vibration is at 1000, 1200 and 1400 RPM (rotation per minute). Noise that occurs at rounds 1000 to 1400 is above the threshold that is greater than $85 \mathrm{~dB}$. If this exposure occurs for a long time, hearing loss will likely to occur. Likewise, the vibration caused by the tractor engine, on the hand shaft at 1000 rotation the vibration acceleration that occurs is $0.67 \mathrm{~m} / \mathrm{s}^{2}$ and at 1400 rotation the acceleration that occurs is $1.19 \mathrm{~m} / \mathrm{s}^{2}$. The vibration threshold values for arm and hand exposure according to the Indonesian National Standardization Agency are as follows:

TABLE V. VIBRATION THRESHOLD VALUES [5]

\begin{tabular}{|c|c|c|}
\hline \multirow{2}{*}{$\begin{array}{c}\text { Exposure hours per day } \\
\text { working hours }\end{array}$} & $\mathrm{m} / \mathrm{sec}^{2}$ & Acceleration Value at Domain Freq. \\
\cline { 2 - 3 } $4<\mathrm{x}<8$ hours & 4 & 0.40 \\
\hline $2<\mathrm{x}<4$ hours & 6 & 0.61 \\
\hline $1<\mathrm{x}<2$ hours & 8 & 0.81 \\
\hline $\mathrm{x}<1$ hour & 12 & 1.22 \\
\hline
\end{tabular}

Noise will have a negative effect on work power if the noise intensity is above $85 \mathrm{~dB}$ continuously, this will cause damage to the sense of hearing [2]. While the vibration that is directly felt by workers is hand contact with the handle of the tractor. This vibration will give a negative physiological effect. There are at least two symptoms in workers caused by the existence of this vibration, namely: abnormalities in blood circulation and nerve damage to the joints and bones [1], [7]

Looking at the environmental conditions of the plowing farmers, it is necessary to have an ergonomic intervention to reduce the additional workload in the form of exposure to heat, noise, and hand tractor vibration for farmers. 


\section{Workloads}

Objectively workload can be predicted using work pulse, while subjectively workload can be predicted from skeletal muscle complaints and general fatigue [8]. The pulse rate calculation can then proceed with the calculation of Cardio Vascular Load (CVL), ECPT (Extra Calorie due to Peripheral Temperature), and ECPM (Extra Calorie due to Peripheral Metabolism).

The results of the calculation of the pulse on the subject before work (rest pulse) and after work (working pulse) are presented in Table 6 below.

TABLE VI. PULSE MEASUREMENT ON FIELD WORKERS WORKING WITH TRACTORS

\begin{tabular}{|c|c|c|c|c|}
\hline Variables & Mean $(\mathrm{ppm})$ & $\mathrm{SD}$ & $\mathrm{t}$ & $p$ \\
\hline Rest Pulse & 70.31 & 4.25 & & \\
\cline { 1 - 3 } Working Pulse & 129.78 & 5.12 & & \multirow{2}{*}{29.047} \\
\hline
\end{tabular}

Table 6 shows that the workload for the fieldworkers using hand tractor is classified as a heavy workload. A mean work rate of 129.78 beats/minute is between $125-130$ beats/minutes is heavy [2], where its Cardio Vascular Load (CVL) was measured at $56.59 \%$. The combination of CVL and WBGT (Wet-Bulb Globe Temperature) values can be seen in Figure 1 below:

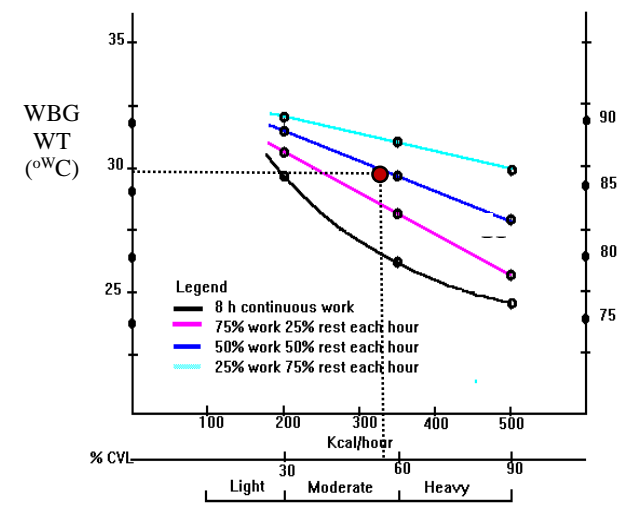

Fig.1. Work and Resting Time Graphic based on WBGT and \%CVL

Based on the graph in Figure 1 above, it can be seen that with \% CVL and WBGT values obtained from field workers in Tabanan Regency, they should divide the work with a 50\% share of working time and a 50\% resting time. Evaluation of workload is important to be used as a basis for making interventions or improvements to the work system of farmers/field workers [9].

The results of the calculation of musculoskeletal complaints were recorded with the Nordic Body Map questionnaire and General Fatigue measurements using 30 questionnaire items are presented in Table 7 below.
TABLE VII. MUSCULOSKELETAL COMPLAINTS AND SUBJECTIVE COMPLAINTS RESULT ANALYSIS

\begin{tabular}{|c|l|c|c|c|c|}
\hline \multicolumn{2}{|c|}{} & Average Score & SD & $\mathrm{t}$ & $\mathrm{P}$ \\
\hline $\begin{array}{c}\text { Musculoskeletal } \\
\text { Complaints }\end{array}$ & Before Work & 37.52 & 1.47 & \multirow{2}{*}{-37.438} & \multirow{2}{*}{0.001} \\
\cline { 2 - 4 } & After Work & 78.65 & 3.50 & & \\
\hline General Fatigue & Before Work & 32.15 & 0.49 & \multirow{2}{*}{-26.602} & \multirow{2}{*}{0.001} \\
\cline { 2 - 4 } & After Work & 52.22 & 2.55 & \\
\hline
\end{tabular}

Musculoskeletal Complaints and General Fatigue as shown in Table 7, there was a significant increase between measurements before work and after work. After work, skeletal muscle complaints that occur in the field workers occur in the shoulder, at the waist (100\% of workers), and pain in the neck, upper left and right arm, and back pain $(80 \%$ of workers). While fatigue that occurs is fatigue in the entire body, pain in the back and feeling thirsty (100\% of workers), then also feel heavy on the head, legs feel heavy, stiff or awkward in motion, stiff in the shoulder, and the body feels shaky obtained $80 \%$ of workers. If these complaints are not given a good solution and the worker continues to get the complaint, it will have a detrimental effect on the health side of the worker [10], [11].

Workload is usually caused by motion and stress. In addition to the effects of motion or metabolism, increased workload can also be caused by the influence of the work environment such as solar heat, noise, and vibration. High temperatures or hot sun can have a big influence on increasing the load. The results of the analysis of the influence of physical work and the influence of the work environment can be measured using ECPT (extra cardiac pulse due to temperature) and ECPM (extra cardiac pulse due to metabolism). ECPT and ECPM measurement results are presented in Table 8 below.

TABLE VIII. ECPT AND ECPM RESULTS ANALYSIS

\begin{tabular}{|c|c|c|c|c|}
\hline & Average & SD & $t$ & $\mathrm{P}$ \\
\hline ECPT & 30,18 & 3,37 & 3,491 & 0,142 \\
\cline { 1 - 3 } ECPM & 29,89 & 4,06 & & \\
\hline
\end{tabular}

Based on the ECPT and ECPM values as in Table 7, it is obtained that the ECPT value is not significantly different from the ECPM value, meaning that the ECPT value can be considered equal to the ECPM value. The definition of the calculation of ECPT and ECPM is as follows [8].

a) ECPT value > ECPM, meaning that environmental factors are more dominant so as to provide additional workload to the subject. In an effort to improve the environmental aspects must be suppressed as small as possible.

b) Value of ECPM > ECPT, means that the physical work of the task performed is indeed heavy. Intervention efforts are aimed at reducing the main workload.

c) $\mathrm{ECPM}=\mathrm{ECPT}$ value, it means that the physical burden of work and environmental aspects both burden the body; thus intervention efforts are aimed at both.

From the calculation results, the ECPT is not significantly different from the ECPM value, this shows that the main task 
factors and work environment factors (local micro climate) both provide a heavy workload on farmers. It also shows that work activities plowing the fields are carried out in the open so that farmers are exposed to the local micro climate (solar radiation, air temperature, humidity and wind speed) including tractor engine noise and vibration during activities. Therefore, if you want to intervene to improve the implementation of farmer activities by plowing the fields by using a hand tractor, the intervention must be directed at matters relating to the main task factors, work equipment, and the local micro climate. Ergonomic intervention on equipment or work systems and work environment can increase work productivity [12], increase work motivation [13], reduce skeletal muscle complaints and general fatigue [14], [15], so that in general it can improve the quality of life of workers.

\section{CONCLUSION AND SUGGESTIONS}

\section{A. Conclusion}

From the results of the analysis and discussion above, the following conclusions can be drawn.

1. Workload of rice field workers using hand tractors in Bali is included in the category of heavy workloads.

2. Physical work accompanied by exposure to heat, noise and vibration caused by the field workers' hand tractors increases skeletal muscle complaints, namely shoulder pain, waist, pain in the neck, left and right upper arms, and back pain, also increases general fatigue, which is fatigue in the whole body, back pain and feeling thirsty, feeling heavy on the head, legs feeling heavy, stiff or awkward in motion, stiff in the shoulders, and feeling trembling.

3. Efforts to improve the implementation of paddy plow activities using hand tractors can be directed at matters relating to the main tasks, work equipment, as well as to the local micro climate, engine noise and vibration.

\section{B. Suggestions}

Some things that can be suggested for the rice field workers by using this hand tractor include:

1. Set work break hours such as giving a break for \pm 10 minutes every working hour while drinking water.

2. Break times for meals are done under the shade of a tree or provide shade.

3. Using ear plugs while operating a plowing tractor in the field, considering the noise caused by the tractor is high, and coating the sponge on the tractor's handrails so that the vibration is muffled.

\section{ACKNOWLEDGMENT}

The authors wish to give their gratitude to the fellow college at Bali State Polytechnic for their support and to LP3M PNB for their guidance as to the development of this paper.

\section{REFERENCES}

[1] World Health Organization, "Occupational exposure to vibration from hand-held tools," in Protecting workers' Health series no.10, UMEA Universitet, 2016.

[2] K. H. E. Kroemer and E. Grandjean, Fitting The Task To The Human, Fifth Editione A Textbook Of Occupational Ergonomics. London: CRC Press, 2009.

[3] A. Manuaba, "Research and application of ergonomics in developing countries, with special reference to Indonesia," Indones. J. Ergon., vol. 1, no. 1, pp. 24-30, 2000.

[4] M. Yusuf, M. Santiana, and W. D. Lokantara, "Improvement of work posture to decrease musculoskeletal disorder and increase work productivity jewelry worker in bali," in Proceeding International Joint Conferenceon Science and Technology (IJCST) 2017, 2017, pp. 242 247.

[5] BSN, Threshold value for working condition under heat, noise, vibration hand-arm, and ultraviolet sun light exposure, SNI 16-70632004. Jakarta: Badan Standarisasi Nasional, 2004.

[6] A. Manuaba, "Total approach is a must for small and medium enterprises to attain sustainable working conditions and environment, with special reference to Bali, Indonesia," Ind. Health, vol. 44, no. 1, pp. 22-26, 2006.

[7] J. Dul and B. Weerdmeester, "Ergonomics For Beginners A Quick Reference Guide", 2nd Edition, 3rd ed. London: Taylor \& Francis, 2008.

[8] N. Adiputra, "Pulse Rate and Its Use in Ergonomics," Indones. J. Ergon., vol. 3, no. 1, pp. 1-6, 2002.

[9] M. Yusuf, N. Adiputra, I. Dewa, P. Sutjana, and K. Tirtayasa, "The Improvement of Work Posture Using RULA (Rapid Upper Limb Assessment) Analysis to Decrease Subjective Disorders of Strawberry Farmers in Bali," Int. Res. J. Eng. IT Sci. Res., vol. 2605, no. 9, pp. 4290-2016, 2016.

[10] S. Pheasant and C. M. Haslegrave, "Bodyspace: Anthropometry, Ergonomics and the Design of Work", 3rd ed. Boca Raton: CRC Press., 2016.

[11] M. Helander, "A Guide to Human Factors and Ergonomics", vol. 51, no. 6. 2006.

[12] M. Yusuf, A.A. Mulawarman, and I. M. Suarta, "Application short rest and gives snack can dercreased workload and musculoskeletal disorder and can increased work productivity for worker chips stir fry in Sanggulan Hill Kediri Village Tabanan regency," in Proceedings - Ergo Future 2006, International Symposium on Past, Present and Future Ergonomics, Occupational Safety and Health, 2006.

[13] I. N. Sutapa, I. Santiana, M. Yusuf, and W. D. Lokantara, "Ergonomic Chair Design for Nursing Mothers to Increase Motivation of Exclusive Breastfeeding,” J. Adv. Sci. Lett., vol. 23, no. 12, pp. 12182-12185, 2017.

[14] I. G. Santosa and M. Yusuf, "The Application of a Dryer Solar Energy Hybrid to Decrease Workload and Increase Dodol Production in Bali," Int. Res. J. Eng. IT Sci. Res., vol. 3, no. 6 SE-Articles, Nov. 2017.

[15] I. K. G. J. Suarbawa, M. Arsawan, M. Yusuf, and I. M. Anom Santiana, "Improvement of environment and work posture through ergonomic approach to increase productivity of balinese kepeng coin workers in Kamasan village Klungkung Bali,” J. of Phys., Conf. Series, vol. 953,. $1,2008$. 